\title{
GULLIVER DORMIDO: UN ESPACIO PARA LA REFLEXIÓN Y LA CRÍTICA
}

\author{
GULLIVER DORMIDO: A MOMENT FOR REFLEXION AND CRITICISM**
}

\section{Mayela Vallejos Ramírez*}

\author{
"Todo texto es la absorción o \\ transformación de otro texto"
} Julia Kristeva

\begin{abstract}
RESUMEN
Este artículo se enfoca en la figura del gigante dormido que viene a conmocionar a las diferentes instituciones de la sociedad costarricense con su aparición en la Sabana. El gigante despierta la curiosidad, el miedo, la expectativa de los diferentes sectores políticos que no saben cómo interpretar la aparición de este hombre descomunal. Cada grupo piensa como usarlo para su propia conveniencia. Al comprobar que el gigante tiene su propia agenda tratan de paralizarlo para que no destruya la armonía que según ellos vive la sociedad costarricense. La ironía, la sátira y la parodia que caracteriza este texto crean un ambiente crítico sobre la sociedad costarricense, sus instituciones sociales y políticas.
\end{abstract}

Palabras clave: Rovinski, gigante, corrupción, democracia, apariencias.

\begin{abstract}
This article focuses on the figure of the sleeping giant that comes to shock the various institutions of Costa Rican society with its appearance in the Sabana. The giant arouses curiosity, fear, and expectation of different political sectors, who do not know how to interpret the appearance of this extraordinary man. Each group thinks of using him for their own convenience. Finding that the giant has its own agenda, they try to paralyze him before he destroys the harmony which they claim lives in the Costa Rican society. The irony, satire and parody that characterize this text create a critical environment of Costa Rican society, and its social and political institutions.
\end{abstract}

Key Words: Rovinski, giant, corruption, democracy, appearance. 
El desarrollo del teatro en Costa Rica a diferencia de otros países latinoamericanos es un fenómeno relativamente reciente. Este ha sido marcado por un teatro de carácter social en dónde se ha retratado la sociedad costarricense desde un punto de vista crítico e irónico. Es probable que las décadas del 70 y 80 sean las más productivas y significativas para la dramaturgia costarricense. Dentro de este periodo nos encontramos la producción teatral de Samuel Rovinski (1932-2013), junto a la de Daniel Gallegos (1930) y Alberto Cañas (1920). Álvaro Quesada señala que la obra teatral de Rovinski está claramente marcada por dos vertientes temáticas, una que tiene que ver con el aspecto popular, de tipo costumbrista pero adaptado a la crítica social y política de situaciones contemporáneas en donde se destacan sus obras Gobierno de Alcoba (1967) y Las fisgonas de Paso Ancho, (1971). La otra vertiente "manifiesta su preocupación por los temas políticos y sociales, y explora las relaciones conflictivas entre el individuo, las estructuras sociales y las instancias del poder" (1993:78). Las obras más sobresalientes de este periodo son El martirio del pastor (1981), La víspera del sábado (1983), y Gulliver Dormido (1985). En estas obras se puede apreciar un trabajo más dramático donde "muestra como rasgo común la preocupación por las consecuencias destructoras y deshumanizantes de la intolerancia, la violencia, la represión de unos contra otros, por razones políticas, culturales o ideológicas" (Quesada, 1993: 78). De estas tres obras antes mencionadas, Gulliver dormido es probablemente la más relevante por tener un manejo técnico mucho más complejo. Otro aspecto es el elemento intertextual que se presenta con la novela del irlandés Jonathan Swift, Los viajes de Gulliver, (1726). En esta novela Swift presenta de una manera satírica, una crítica mordaz a la sociedad europea de su época. El personaje central de esta novela, Lemuel Gulliver es el narrador quien nos relata sobre sus viajes fantásticos a tierras desconocidas y sus múltiples aventuras. Es a través de esos viajes y los diferentes encuentros con grupos diversos que puede hacer su crítica política y social. Esto le permite llegar a la conclusión que no existe ninguna forma ideal de gobierno, que los seres humanos tienen tendencia a la corrupción pero que siempre van a existir personas que actúan bien a pesar de todo. La novela es sumamente compleja y presenta una clara dicotomía de los aspectos relacionados con el personaje central y los diferentes tipos de personas que encuentra durante todos sus viajes. Gulliver aparece como un gigante versus un enano, un sabio versus un ignorante en contraste con los gobiernos que irrumpen como lo peor o lo mejor dependiendo de la perspectiva que se quiere resaltar. Lo más sobresaliente es que el escritor irlandés magistralmente se cuida de no dirigirse o criticar a un grupo particular de la sociedad sino que plantea generalizaciones que permiten al lector comprender mejor la situación que vive la sociedad inglesa del momento. Simon Varey considera que:

Gulliver's Travels is analogical rather than
allegorical, and its generality emerges only
through specific allusions. I shall argue than it is
simultaneously a satire and a species of history: so
rather than search for alternative identifications, I
should consider the analogical technique of Swift's
political satire in Gulliver's Travels in light of his
conception of historiography. In common with so
many of his contemporaries, Swift accepted that
human nature was generally uniform and therefore
did not change fundamentally from one age to the
next or from one European culture to another. He
also subscribed to the concomitant theory that
history is cyclical. (1992:42)

Este breve acercamiento a la novela de Swift nos permite observar que en la obra de teatro Gulliver dormido la intertextualidad ${ }^{1}$ funciona como una alusión al texto principal. El referente es el aspecto satírico de cómo se trabaja el asunto político y el actuar de los seres humanos en sociedad. El texto es relevante al original con respecto al discurso y la utilización que se da del mismo en forma global para reelaborar la idea principal que es una mordaz crítica del discurso político oficial. Si Swift consideraba que la naturaleza humana es la misma y que la historia es cíclica, entonces, la utilización del símbolo del gigante en manos 
de dramaturgo costarricense tiene sentido. Los problemas de la humanidad son los mismos y pueden ser representados con los mismos símbolos en diferentes culturas. Cabe aclara que no se trata de una re-escritura ${ }^{2}$ del texto de Swift. Este nuevo Gulliver no se embarca en una serie de aventuras en alta mar. En la obra de Rovinski, Gulliver es una alegoría de la sociedad costarricense: "Gulliver dormido es una enorme farsa, es un gran fresco, es una gigantesca radiografía de la sociedad costarricense, irreverente, llena de humor y frescura" (Bonilla, contraportada). No realiza viajes fantásticos, no se encuentra con personajes extraños, no está en control de su propio destino, ni presenta su punto de vista por carecer de una voz. La mayor parte de la obra se encuentra adormilado por la fuerza pública que se ha empecinado en mantenerlo bajo control. Concordamos con Mario Rojas cuando señala en su artículo "Gulliver dormido de Samuel Rovinski: una parodia del discurso del poder" que este personaje a diferencia del Gulliver original, no tiene un protagónico convencional, no puede hablar, apenas si puede emitir ruidos extraños, incomprensibles para el resto de la sociedad. "Gulliver carece de voz, al estar sumido en un profundo sueño en una buena parte de la obra, y cuando despierta los sonidos que emite carecen de referente, no son más que ruidos atronantes que permanecen solo en su materialidad significante" (1985:52). Como se puede observar, nuestro Gulliver tiene otra función que está más relacionada con producir un despertar en la conciencia del espectador a través de la influencia que produce en los otros por su solo presencia disruptiva. "Gulliver carece de palabra, pero paradójicamente, su mudez estimula la palabra, haciendo estallar con su presencia una incontenible avalancha de discursos que irrumpen de boca de las autoridades del país en un torrente retórico" (Rojas, 1990: 52).

Otro aspecto que diferencia al Gulliver de Rovinski es que siempre es visto como un hombre de tamaño descomunal, mientras que en el texto de Swift, Gulliver solo aparece como gigante en la primera parte de la novela cuando se encuentra con los liliputienses. Estos seres pequeñitos al igual que las autoridades costarricenses amarran al gigante hasta que pueden comprobar que este no es una amenaza para ellos. Luego aprenden a convivir con él y lo hacen su aliado contra los Blefusar. Sin embargo, Gulliver se ve obligado a huir de los pequeños liliputienses cuando se niega a seguir conspirando contra el otro pueblo y con esta actitud se gana la enemistad del rey. Este es probablemente, el capítulo más divulgado del libro de Swift y el que muestra una tremenda crítica a la mezquindad de los liliputienses. Por lo tanto, el concepto de Gulliver como un gigante es el que se desarrolla en esta obra teatral. En ese aspecto, la actitud de los políticos costarricenses se asemeja al texto original, ya que todos ambicionan el apoyo incondicional del gigante para seguir controlando el pueblo a su antojo como se puede apreciar en la siguiente cita: "El apoyo de esta gran fuerza al gobierno traerá el progreso y la consolidación de nuestra tradicional democracia y vendrá a fortalecer las instituciones que han hecho de nuestro país un ejemplo para el mundo" (Rovinski, 1985: 164165). Es interesante que no solo el gobierno, sino otros grupos políticos, como los comunistas y el partido contrario al gobierno afirmen haber conseguido el apoyo del gigante sin ser la realidad, como lo expresa uno de los policías: "Pero todos salen asegurando que hablaron con él; y parecen cambiados, viendo hacia el cielo, como si se hubieran encontrado con la Virgen... (Rovinski, 1985: 172). Lo cual nos deja ver la falsedad que rodea a los políticos que con tal de manipular la opinión popular son capaces de crear todo un circo a su alrededor y mentir frescamente: "Mirá, Chalo... Yo no me he movido de aquí ni para mear y te juro que el mamulón no levantó una pestaña... Está más dormido que un muerto" (Rovinski, 1985: 173). Es obvio que no existe un diálogo verdadero entre el gigante y el gobierno costarricense y menos aún entre otros grupos políticos minoritarios. Apréciese en estas líneas la desesperación que siente el presidente ante la incapacidad de comunicación y poder averiguar lo que todo este caos realmente representa para el gobierno y el país: "Tenés que averiguar lo que realmente quiere y que se 
propone hacer... Vas a buscar una fórmula de arreglo, pero que no violente nuestra tradición democrática (Rovinski, 1985: 189). Si bien es cierto que le preocupa la incertidumbre, está más ansioso por salvaguardar las apariencias. Al final, el gobierno no logra entender lo que verdaderamente motivó a este ser gigantesco a aparecer en la sábana. Lo cual muestra la incapacidad de los políticos por comprender las necesidades del pueblo, especialmente los estratos más bajos de la sociedad. Obsérvese que la única persona que logra comprender lo que desea el gigante es la anciana vendedora de dulces que dice saber qué es lo que quiere el gigante, lo cual es muy significativo porque esta mujer es la que representa las masas populares que realmente son las que sufren en carne propia la crisis:

Viejecita: ¿Y cómo no lo voy a saber? ... Si por eso estoy aquí... Ese manganzón se comió todas mis cajetas y prestiños y pidió más; y si no le quito la canasta capaz que me come a mí... Entonces, le pedí que me pagara, ¿y saben que me contestó?

Todos: (Volcándose sobre ella) ¿Qué le contestó?

Viejecita: (Imita con tono grave) ¡Tengo haaambre!

Presidente: ¿Hambre?

M.P: ¿Solo eso?

Viejecita: ¿Qué más le pide el corazón? ¿Con hambre no es suficiente?

Es evidente la incapacidad del gobierno por entender que el hambre es uno de los factores más determinantes para que un pueblo produzca cambios, sino recordemos la Revolución Francesa ${ }^{3}$. Sin embargo, en este caso el gobierno se pone manos a la obra y empieza a alimentar el insaciable gigante que va devorando poco a poco todas las provisiones que hay en el país, causando un caos mayor a los destrozos materiales que estaba ocasionando al principio cuando se despertó. Es increíble que la incomunicación siga prevaleciendo. Se limitan a alimentarlo pero no intentan realmente investigar que podría traer un verdadero cambio en su actitud. Esto nos remite a lo que muchas instituciones realizan en el gobierno en la actualidad, como son los innumerables bonos otorgados a la población. Calman las necesidades pero no solucionan los problemas de raíz. Se ha creado un gobierno paternalista que en vez de enseñar a sus hijos a trabajar los mantiene contentos con dádivas haciendo de ellos personas dependientes y minusválidas laboralmente. No existe un verdadero diálogo ni se produce una situación óptima para el cambio. Se juega constantemente con la integridad de las personas. Cada contienda electoral se compran las conciencias de los pobres con regalos materiales que calman el hambre y las necesidades momentáneamente pero realmente no resuelve la pobreza en la que se encuentra ceñido un gran sector de la sociedad.

Aparentemente nos encontramos ante dos gigantes muy diferentes. Sin embargo, ambos nos permiten crear una pintura fehaciente de la sociedad en la que surgen. Es claro que en el texto del irlandés apunta a la política inglesa de ese momento histórico. Swift plantea a través de los diferentes territorios que visita Gulliver su propia perspectiva política y social a modo de ejemplos: "Gulliver's Travels also fulfills the function of exemplary history in that the ruler of each land puts Gulliver on trial in order to judge men's actions" (Varey, 1992: 51). Por su parte, Rovinski utiliza la figura del Gulliver para plantearnos su preocupación por los acontecimientos políticos y sociales que se estaban presentando en ese momento histórico en Costa Rica. En fin, esta obra teatral nos muestra un periodo de decadencia política y económica: "Como se ha venido mencionando, durante la primer mitad de la década de los ochenta estalla una grave crisis económica que usualmente ha sido interpretada como signo del agotamiento de un modelo de desarrollo que el país siguió durante épocas anteriores" (Castillo, 2005: 248). En ese momento, el país se vio sorprendido por un gigante que amenazaba la estabilidad economía y social. El pueblo realmente estaba maniatado ante el desplome económico y daba la impresión que nadie sabía con certeza que hacer ante la magnitud del problema. "La devaluación fue la expresión más clara de la insolvencia 
externa de la economía, paralelamente a la magnitud del desequilibrio fiscal y a una deuda externa grandísima" (Castillo, 2005: 249). Estos acontecimientos son los que tiene de trasfondo esta extraordinaria pieza teatral. Sin embargo, lo más interesante es la vigencia que aún sigue manteniendo esta obra hasta nuestros días en parte porque el dramaturgo no se enfocó simplemente en el problema económico-social pero en la coyuntura político-social reflejo de una idiosincrasia nacional.

Por esta razón queremos también analizar algunas frases clichés usadas por el discurso oficial y explicarlas en el contexto políticosocial actual ya que esta obra aún mantiene una gran vigencia con el actuar de los políticos de este país y me atrevería a afirmar que del mundo entero variando por supuesto el contexto sociopolítico. La obra como bien lo afirma Ana Elena Castillo en su artículo "Acerca de ese gran acontecimiento el enorme sujeto: El Gulliver dormido que apareció en la Sabana... "es una reflexión sobre la crisis que vivió el país en la década de los 80. El gigante se asocia con la inesperada crisis que sumió al gobierno y por ende al pueblo costarricense en un gran caos,

\begin{abstract}
Es importante acotar que, efectivamente, el sujeto (en este caso podemos observarlo literalmente en la enorme forma de un Gulliver) tiene su génesis de forma local, coyuntural. Hay una gran crisis económica en el país, con una situación muy complicada producto de malas decisiones en los planeamientos estratégicos del Gobierno, una crisis mundial, un alza en los precios del petróleo, una caída en los precios del café y todo ello desemboca en caos social, donde, precisamente, el golpe más evidente se da por la falta de comida y abastecimientos básicos. La inflación llega a niveles desorbitantes que perjudica directamente a la clase popular en lo más elemental: su sustento diario. (2005: 256)
\end{abstract}

El manejo del lenguaje es fundamental en esta pieza porque es el arma que se usa para plantear la problemática política del país. María Lourdes Cortés considera que "En Gulliver dormido, el pueblo está adormecido y engañado, y por ello es incapaz de general un cambio. Este texto pretende señalar los elementos disfuncionales de una democracia casi perfecta como la costarricense y advertir sobre lo que pasaría si algo inesperado, un elemento externo, interrumpiera en esta paz" (1987:46). Este comentario es sumamente importante porque nos lleva a meditar en uno de los grandes mitos costarricenses "una democracia casi perfecta". Si bien es cierto que Costa Rica ha gozado de una paz y tranquilidad envidiable en comparación con otros países de la región, como bien se señala en el texto refiriéndose a la década de los 80 cuando la mayoría de los países centroamericanos estaban sumidos en sangrientas guerras civiles: "Cuando en el resto de nuestra sufrida Centroamérica, los extremistas de izquierda y derecha se enfrascan en una sanguinaria lucha fratricida, nuestra querida Patria, flota como un remanso de paz en medio de la vorágine guerrera" (Rojas, 1990: 52). Tampoco es cierto que seamos la Suiza centroamericana con las implicaciones que esta frase conlleva. Y menos aún que seamos el país más feliz del mundo como nos han hecho creer las encuestas amparado por la frase chiché más tica, "pura vida". Nuestra cultura se ha cimentado especialmente en las últimas décadas que todo está "pura vida" aunque la verdad es que el país está luchando contra un gigante dormido que mantiene maniatada la pobreza, la ignorancia, la corrupción, la falta de empleos solo por mencionar unos cuentos de los problemas que afloran como la punta del iceberg de vez en cuando. ¿Qué hará el costarricense cuando esta mampara de país perfecto se caiga? ¿Qué hará el gobierno cuando ya no puede sostener instituciones como el IMAS y la caja costarricense de seguro social que crean una sensación de estabilidad a la población? Mario Bermúdez considera que

\footnotetext{
$\mathrm{Ni}$ el pesimismo derrotista, ni la exaltación chovinista. Costa Rica se encuentra en una etapa de transición histórica que demanda realismo. Sin embargo, el país pareciera estar preso de dos visiones totalmente opuestas, en las que se pregona que vivimos en el país más feliz y más seguro del mundo, o las voces de quienes vaticinan el inminente apocalipsis de toda la institucionalidad (Blogs 2013)
} 
Este comentario nos devuelve a lo citado anteriormente por María Lourdes Cortés, "el pueblo está adormecido y engañado, y por ello es incapaz de general un cambio" (1987:46). A través del texto podemos encontrar múltiples acotaciones que se refieren a la necesidad de controlar el actuar de este ser descomunal que desde nuestra perspectiva representa al pueblo, más que una crisis: “vamos a dormirlo”(1985:155), “dormido y paralizado”(1985:155), “ ¡A los gigantes hay que dominarlos!" y "Hay que paralizarlo"(1985:221). De esta manera, es como ha vivido un gran sector de la población, dormida, sumida en un profundo sueño. Provocar al gigante dormido sería catastrófico para el país porque eso causaría un despertar de conciencias, sería exponer a un pueblo "domesticado" como nos llamara Don Pepe en son de broma y burla. La frase nunca impactó la población que lo vio como una de "las salidas de don Pepe", pero que en verdad es una dolorosa realidad. Sin embargo, la seguimos repitiendo en tono burlesco como parte de la idiosincrasia del tico que ve con indiferencia la realidad nacional:

\begin{abstract}
Y esta domesticación no es nada: la actitud filosófica del costarricense es, aunque duela decirlo, la de una gallina que sólo cacarea y nunca pone el huevo. Cuántas personas que se encuentra uno a diario hablan de lo mal que está esto o aquello; de la corrupción rampante, cuya eliminación ha sido un mito político de los últimos años; de que Vesco será ya, en menos de un año, un compatriota nuestro, junto a los Mora, Cañas, Guardia y Castro Madriz; de que la vida es insoportable; de que la burocracia nos agota; de que ya no se puede trabajar sin estar bien con los políticos poderosos; de que estamos a punto de caer en un partido único (¿a punto?; ¿no estaremos ya?); de que las libertades de expresión se cercenan cada vez más y de que el derecho a la propiedad se erosiona hacia un control estatal cada vez mayor. Hasta que aburren con esas poses que los dignifica. ¿Por qué no hacen nada?, ¿tienen miedo? ¿No es esa la domesticación de que nos habla Figueres? (Corrales, 1975: La Nación)
\end{abstract}

Otro aspecto que cabe señalar aquí es la falta de responsabilidad que ha caracterizado a nuestros políticos. "Mira, no sé de dónde vino... Pero, si no me equivoco, es obra de los extremistas" (1985:154). Es la actitud más fácil, culpar a los otros por la ineptitud de los que llevan las riendas del país. Eso los hace aparecer como los sacrificados que tienen que luchar contra aquellas personas antipatrióticas que no colaboran con el progreso del pueblo porque son profetas de calamidades: "Nosotros sostendremos la democracia, la justicia y la paz contra todas las amenazas de los pusilánimes y los enemigos de la patria..." (1985:165). En la actualidad ese sigue siendo un discurso muy familiar que es utilizado para desprestigiar aquellas personas que quieren despertar del letargo en que hemos vivido. Sino recordemos un poco la campaña de desprestigio que se hizo contra las personas que lucharon a brazo partido contra el TLC (Tratado de Libre Comercio) que culminó con el Referéndum del 7 de octubre de 2007 a favor del gobierno. De la misma manera, la lucha que se ha dado contra las personas que han luchado por no perder instituciones orgullosamente costarricenses como el ICE con la apertura comercial. La versión oficial es que todo lo que hace el gobierno es por el bienestar del pueblo pero al final de cuentas es el que menos cuenta. Esto en la obra de teatro se ejemplifica con la vendedora de dulces que va de un sitio a otro sin casi ser percibida por los oficiales gubernamentales.

El último aspecto que queremos tratar es la intervención extranjera que aparece de una manera sutil. Con la aparición del gigante en la Sabana, se apersona al lugar de los hechos el señor embajador que está sumamente preocupado que este ser descomunal. Este podría producir estragos en la sociedad los cuales afectarían indirectamente al gobierno que representa. Lógicamente, el ministro de seguridad asegura que todo se tiene bajo control porque su gobierno "no tolera gigantes con doctrinas exóticas" (1985:177). El embajador le asegura que en caso de que el gobierno local no puedo controlar a esta fuerza: "estoy autorizado por mi gobierno para ofrecerle armas y un grupo de asesores" (1985:177). Lo cual apunta a la intromisión extranjera que sufren países como el costarricense por parte de las grandes potencias que no los creen capaces de gobernarse. Se puede apreciar el empeño que pone el gobierno por demostrar que son autosuficientes y capaces 
de controlar los problemas internos, como se aprecia en este corto diálogo:

M.S.: ¡Son infundios! El gigante sigue dormido y amarrado.

Embajador: Trate de mantenerlo sujeto, señor Ministro..., pero no lo maltrate. Hay que respetar los derechos humanos.

MS: (ofendido) Pero, señor Embajador, me extraña, nosotros somos gente civilizada. (1985:221)

Se puede apreciar dos aspectos importantes. Por un lado, la doble moral que se presenta cuando se trata de silenciar al enemigo. Se requiere de ser firmes pero dar una imagen de país democrático y civilizado respetuoso de los derechos humanos al resto del mundo. Por otra parte, hay que acallar las fuerzas que atentan contra la seguridad nacional sin tener ningún miramiento como se ve al final de la obra en las palabras del Ministro de Seguridad: "Sí, señor, estamos preparados... Le vamos a administrar una dosis que lo tendrá mucho tiempo fuera de acción" (1985:221). Como se puede observar, el gobierno está preparado para hacer lo que sea necesario para restablecer la armonía. Es importante que todas las instituciones nacionales e internacionales sientan que pueden confiar en el gobierno a pesar de todos sus desaciertos.

En conclusión, una primera lectura de Gulliver dormido nos hace pensar en una obra de carácter fantástico, rodeada de elementos absurdos, ilógicos e irónicos. Sin embargo, los planteamientos políticos y socioeconómicos que se presentan en esta obra nos dejan sopesar muchos aspectos importantes de la idiosincrasia del costarricense. El discurso que se emplea permite al lector o espectador asociarlo no solo con la crisis de los 80 , sino con una problemática actual porque esta obra va mucho más allá de un momento específico de la historia costarricense. El elemento universal le da una gran vigencia porque el discurso del poder que han utilizado los políticos y otros grupos de la sociedad sigue siendo el mismo. Además, esta pieza teatral abarca un gran sector de la sociedad y critica ciertas actitudes que caracterizan el ser costarricense por medio de mitos, ideologías y actitudes ante el acontecer sociopolítico. La alusión que hace el dramaturgo "al gigante dormido" con relación al pueblo costarricense, es sumamente evidente y actual. "Y que vamos a hacer cuando se despierte de nuevo? Le pregunta el ministro de la presidencia al señor presidente: "Para entonces se me habrá ocurrido otra idea..." (221).

\section{Notas}

1. El término de intertextualidad fue usado por primera vez por Julia Kristeva al referirse al trabajo de Bajtin en su artículo "Bajtin, la palabra, el diálogo y la novela" en Critique. Kristeva considera que todo texto se construye como un mosaico de citaciones y que a la vez absorbe y transforma el otro texto. De la misma manera Roland Barthes en "Teoría del texto" se refería a la intertextualidad como "Todo texto es un intertexto. Hay otros textos presentes en él, en distintos niveles y en formas más o menos reconocibles: los textos de la cultura anterior y los de la cultura contemporánea. Todo texto es un tejido realizado a partir de citas anteriores (...) La intertextualidad, condición indispensable de todo texto, sea cual sea, no puede reducirse evidentemente a un problema de fuentes o influencias" p.1015. En el caso particular de Gulliver dormido la intertextualidad funciona como una alusión. Este diálogo intertextual lo que le permite al lector es hacer relaciones con el texto original. Lo cual permite que se el lector pueda apreciar las diferencias entre los dos manteniendo siempre la relación original que existe entre los dos.

2. Por re-escritura me refiero a la repetición del texto original con variaciones específicas.

3. Movimiento revolucionario que culminó con la toma de la Bastilla el 14 de julio de 1789. Si bien es cierto que no solo el hambre fue el factor detonante de esta revolución, la escasez de alimentos y el descontento de las masas populares frente a la indiferencia de un gobierno absolutista contribuyó grandemente a este proceso político.

\section{Bibliografía}

Bermúdez, Mario. 2013. "Desmitificando al país más seguro y feliz del mundo" 
www.el financiero.com/blogs/poli-tica/ seguridad-felicidad-costa rica-mitos.

Castillo Víquez, Ana Elena. 2005. “Acerca de ese gran acontecimiento: el enorme sujeto, El Gulliver dormido que apareció en la Sabana". Káñina. (245-256).

Cortés, María Lourdes. 1987 “La ocultación de las contradicciones de clase en la dramaturgia costarricense". Escena 18. (45-48).

Corrales Quesada, Jorge. 1975 “Un pueblo domesticado" La Nación.
Rojas, Mario A. 1990. “Gulliver dormido de Samuel Rovinski: Una parodia del discurso del poder". Latin American Theatre Review. (51-63).

Rovinski, Samuel. 2008. Las fisgonas de Paso Ancho, Gulliver dormido y otras obras. San José: Editorial Costa Rica.

Swift, Jonathan. Gulliver's Travels. 1992. Hertfordshire: Wordsworth Editions.

Varey, Simon. 1992. "Exemplary History and the Political Satire of Gulliver's Travels". The Genres of Gulliver's Travels. Ed. Frederik N. Smith. New Jersey: Associated University Press.

\section{@ $\mathbb{\oplus \Theta \Theta}$}

Este obra está bajo una licencia de Creative Commons Reconocimiento-NoComercial-SinObraDerivada 4.0 Internacional. 